\title{
O PLANEJAMENTO NA EDUCAÇÃO FÍSICA ESCOLAR: UM POSSÍVEL CAMINHO PARA A FORMAÇÃO DE UM NOVO HOMEM*
}

\author{
Marcelo Nunes SAYÃO** \\ NeYSE LuZ MunIZ***
}

\section{RESUMO}

Este texto procura apontar para a importância de se construir um planejamento baseado numa referência de sociedade e de homem. A partir daí, apresenta um exemplo de planejamento para a educação física escolar baseado em uma concepção de sociedade e de homem.

PALAVRAS-CHAVE: planejamento-educação física escolar.

\section{INTRODUÇÃO}

$\mathrm{N}_{\mathrm{e}}^{2}$ a construção de um planejamento nos deparamos com alguns equívocos comuns que precisam ser superados se quisermos construir uma educação de qualidade. O primeiro equívoco diz respeito à concepção de que planejamento deve ser feito apenas no início do ano. Ora, se entendermos que a função do planejamento é organizar a ação docente veremos que a idéia de se construir o mesmo somente no início do ano esconde uma visão do planejamento como algo pontual. Entendemos que isso seja um erro, pois, na verdade, o vemos como um processo e como tal orienta a organização da ação docente que acontece durante todo o ano e está sujeita a alterações impostas pela realidade cotidiana.

Um outro equívoco é a falta de percepção de que o planejamento está estreitamente relacionado à dinâmica da prática cotidiana. Assim,

* Texto construído a partir do trabalho final do Curso de Especialização em Educação Física Escolar da Universidade Federal Fluminense orientado pela professora mestre Neyse Luz Muniz.

** Mestre em Administração Pública pela Fundação Getúlio Vargas e Professor das redes Municipal e Estadual do Rio de Janeiro.

*** Professora do Departamento de Educação Física da Universidade Federal Fluminense. 
ao restringir sua construção ao início do ano o professor não considera, no processo de aprendizagem, questões decorrentes de seu próprio trabalho e muitas vezes copia o que utilizou no ano anterior. Em decorrência disto, o ensino fica cada vez mais destacado de uma realidade que é rica e que se transforma a cada dia.

Mais um engano que tem ocorrido na confecção do planejamento é sua construção ocorrer de forma isolada pelo professor. Como resultado ou causa desta atitude temos um isolamento que faz com que cada um trabalhe por si só sem que se construa um projeto coletivo de escola, de educação e de formação.

Um último equívoco é o que descola o planejamento de um projeto político pedagógico. Quando isso ocorre, o planejamento perde o referencial, pois é utilizado sem se ter clareza de onde se quer chegar, ou seja, em que sociedade se quer viver e em função disto que homem precisa ser formado. Aqui neste ponto nos detemos para discutir a importância de se relacionar o planejamento com os objetivos da formação do sujeito na escola e em função disso que escola devemos ter.

\section{POR QUE PLANEJAR?}

Se for para organizar o trabalho do professor e da escola precisamos saber que objetivos buscamos com esta organização. Nesse sentido, entendemos que restringir o planejamento a um simples instrumento capaz de melhorar a qualidade do nosso trabalho é destituí-lo do seu papel político e revesti-lo de uma suposta neutralidade. Ao fazermos isso estaríamos imersos na ilusão de que o trabalho pedagógico é neutro e não interfere nas características do sujeito que estamos formando.

Libâneo (1994), ao falar da importância do planejamento, afirma que este é um processo que visa a articular o trabalho da escola com a realidade social e que tudo que ocorre no interior da escola está atravessado de significados políticos, econômicos e culturais característicos da sociedade em que vivemos. Prosseguindo, o autor frisa que se não refletirmos sobre estes significados e não atuarmos sobre os mesmos, tentando transformá-los de acordo com as nossas concepções, estaremos apenas reproduzindo o que já existe e assim mantendo a estrutura social intacta. Ora, se concordamos que a sociedade deve continuar do jeito que ela é hoje não temos que nos preocupar em alterar os significados sociais que perpassam o nosso cotidiano, mas se nos encontramos insatisfeitos com o 
que presenciamos é fundamental empreendermos ações que modifiquem as características desta sociedade. É como nos diz Libâneo:

o planejamento é uma atividade de reflexão acerca das nossas opções e ações; se não pensarmos detidamente sobre o rumo que devemos dar ao nosso trabalho, ficaremos entregues aos rumos estabelecidos pelos interesses dominantes na sociedade (1994, p. 222).

No mesmo sentido, Luckesi (1998) afirma que planejar implica uma escolha e envolve juízos e valores sobre uma determinada realidade. Ele ressalta que o planejamento é uma atividade-meio orientada para uma finalidade e que esta contém opções políticas e filosóficas acerca da sociedade na qual vivemos. $\mathrm{O}$ autor faz ainda uma crítica àqueles que defendem o planejamento como uma técnica neutra que deve ser utilizada somente para racionalizar a ação, pois entende que agindo assim

pouco ou nada se discute a respeito do significado social e político da ação que se está planejando. Não se pergunta pelas determinações sociais que estão na base do problema a ser enfrentado, assim como não se discutem as possíveis conseqüências político-sociais que decorrerão do projeto em pauta (LUCKESI, 1998, p. 107).

Luckesi (1998) deixa claro que não está negando a importância de considerarmos o lado técnico do planejamento, pois reconhece que a necessidade de organizar o trabalho de uma melhor forma para que os objetivos possam ser alcançados é facilitada pelo ato de planejar. Defende que o planejamento deve ser ao mesmo tempo técnico e políticofilosófico garantindo uma ação eficiente para alcançar os objetivos, definidos anteriormente, que deverão estar de acordo com os valores relacionados a uma concepção de sociedade.

Devemos planejar então nossa ação pedagógica tendo como balizadores o tipo de Homem que queremos formar e a sociedade que pretendemos ajudar a construir. Esses balizadores nos ajudarão a definir os objetivos a serem atingidos e que, por sua vez, serão os norteadores dos conteúdos com os quais iremos trabalhar e dos procedimentos de ensino que iremos utilizar. 


\section{PARA ONDE DESEJAMOS IR}

Nosso caminho tem início na discrição sucinta da definição de sociedade e de Homem que queremos, para posteriormente apresentarmos um planejamento específico à disciplina Educação Física que ao nosso ver entrelaça nossas intenções com nossa ação pedagógica. Neste processo precisamos, de acordo com Luckesi (1998) e Libâneo (1994), avaliar as características da sociedade e do homem que temos para poder visualizar as mudanças que gostaríamos de efetivar nesta sociedade e neste homem.

\section{A sociedade}

Vivemos em uma sociedade extremamente desigual onde uma minoria privilegiada tem possibilidade de usufruir os bens advindos da mais alta tecnologia enquanto que a grande maioria não tem sequer atendidas as suas necessidades básicas de alimentação, saúde e moradia. Com o desenvolvimento tecnológico alcançado, toda sociedade poderia ter condições de usufruir um alto padrão de qualidade de vida, o que, no entanto, não acontece. Isso, ao nosso ver, é extremamente injusto e precisa ser mudado.

Assim, avaliamos que é necessário construir uma sociedade alternativa a esta, e para isso dois conceitos são primordiais: igualdade e justiça social. Entendemos que essa igualdade deve garantir aos indivíduos uma condição de vida mais digna, na qual todos possam se apropriar e usufruir os bens produzidos pela humanidade. Atrelado a este conceito, pensamos a justiça social como uma necessidade que temos de acabar com a fome, com a miséria, com a ignorância, e buscar uma condição de vida igual para todos.

Partindo dessa visão, nos juntamos a Frigotto (1995), o qual, apoiado nas idéias de Oliveira (1992), Coutinho (1984 e 1991) e Hobsbawm (1992), defende que o caminho para uma sociedade alternativa deve ser o da radicalização da democracia, por uma democracia revolucionária (WEFFORT, 1984). Este tipo de democracia é tido como subversiva, pois contesta a idéia de que o poder vem naturalmente de cima para baixo, seja esse poder político ou econômico. Assim, para que a democracia seja revolucionária, ela deve conter uma predominância dos 
mecanismos de participação, de democracia direta, onde se dê uma intensa participação popular.

Dessa forma, pensamos que o planejamento deve privilegiar objetivos de trabalho, conteúdos e métodos que se enquadrem nessa visão de democracia e que auxiliem na formação de um sujeito participativo. Fica claro aqui que intimamente associada à visão de sociedade está a idéia de homem, assim, acreditamos ser importante falarmos desta estreita relação entre o homem que perseguimos na busca da sociedade que almejamos.

\section{O homem}

No decorrer da História, as diferentes sociedades têm concedido características aos homens que dela fazem parte no que se refere a sua forma de pensar, de viver, de se relacionar com a natureza, com os outros homens e com os bens produzidos através do trabalho. Nas sociedades capitalistas como a nossa, podemos destacar como características marcantes do homem o individualismo e a competitividade exacerbada.

Essas características são marcantes porque na sociedade em que vivemos predomina a idéia de que os direitos são o resultado do esforço individual, e não a de que é a sociedade que deve garantir esses direitos às pessoas.

Guattari (1987) chama atenção para a própria noção de indivíduo, a qual é uma construção que serve à lógica capitalista e ao seu modo de produção e estabelece uma diferenciação entre indivíduo e subjetivida$\mathrm{de}^{1}$. Esse autor esclarece que a primazia do indivíduo sobre o campo social é um instrumento de redução das relações de produção da sociedade capitalista. Portanto, deixamos de perceber as relações de conjunto, o todo, o grupo, a classe para observar os indivíduos isoladamente, o que é fundamental para a captação e subordinação da força de trabalho.

Assim, baseado nessas idéias, pode-se inferir que o predomínio do individual sobre o coletivo aponta a forma como os homens se relacionam com os outros e com a sociedade. Cada um existe por si e para si mesmo, e deve conquistar os bens necessários à sua sobrevivência.

A relação que resulta deste comportamento é a competição, pois para alcançar uma posição melhor na sociedade o homem tem, muitas vezes, que sobrepujar um outro. Está conformada assim uma relação de 
oposição entre os indivíduos, cada um tem que provar que é mais capaz para poder obter mais dinheiro e mais direitos.

Essa lógica acaba sendo tão internalizada que mesmo quando não existe uma posição em disputa os homens acabam estabelecendo entre si uma relação de competição. Dessa forma, ao invés de perceber o seu semelhante como alguém que pode contribuir para construir um espaço comum melhor, nos acostumamos a competir com ele na busca do que é melhor para nós.

Guattari (1987) fala de uma "participação inconsciente" dos sujeitos, a qual se dá a partir do momento em que esses sujeitos reproduzem, seja ativamente ou passivamente, os modelos dominantes da sociedade capitalista. Assim, o autor aponta exemplos do que ele chama de objetos institucionais alienantes, ou seja, a família conjugal e sua repressão intrafamiliar, o patriotismo e seu cunho racista e o machismo. Esses objetos, dentre outros, geram no homem todo um ideal de comportamento imaginário que deve ser seguido e valorizado. Na garantia de efetivação desse comportamento atua não só uma repressão de fora para dentro, mas também um juiz interno, talvez mais eficaz do que qualquer outra instituição de controle, já que produz angústia e sentimento de culpa do próprio sujeito por não seguir de acordo com a "normalidade". Esse controle funciona também se valendo da sugestão coletiva, atualmente muito baseada na força da mídia, que transforma comportamentos particulares em ideais universais e faz com que todos busquem se adaptar a esta universalidade para assegurar sua aceitação pela sociedade.

Nesta perspectiva, Guattari (1987) aponta a necessidade de unir dois tipos de luta para a transformação da sociedade. A primeira é a busca de uma sociedade mais justa em que todos tenham acesso aos bens nela produzidos. Já a segunda diz respeito ao que o autor denomina de lutas do desejo ${ }^{2}$ e está mais ligada à questão da subjetividade.

Nesta segunda luta, o objetivo é que o sujeito passe a não mais tomar como referência a individualidade e a subjetividade burguesas, mas que possa, a partir da liberação do seu próprio desejo, construir uma nova subjetividade, uma vez que esta está sempre em construção e segue as múltiplas possibilidades de ligações que o desejo pode encontrar, sendo assim subversiva, pois romperia com a moral burguesa e todas as suas institucionalizações. Neste caminho nos diz que não devemos nos contentar 
em questionar a forma das relações entre exploradores e explorados, nós atacamos a raiz, a matéria da exploração capitalista-burocrática, isto é, o trabalho assalariado, a aceitação passiva de um corte entre o trabalho e o desejo, o investimento do trabalho como droga de abolição de todos os desejos abertos do mundo (GUATTARI, 1987, p. 61).

Para esse autor, o desejo é revolucionário, agente de construção de um novo devir, de novas possibilidades, o que pode provocar rupturas com as personalidades e subjetividades institucionalizadas pelo capitalismo.

Nesse sentido, acreditamos que a transformação deve estar em nós o tempo todo e que este novo homem deve estar aberto para a diferença e não pode tomar para si, nem cobrar dos outros, que tenham como referencial um modelo de homem instituído pela moralidade burguesa. Se desejamos uma realidade diferente não podemos continuar nos relacionando uns com os outros nos moldes instituídos pela sociedade capitalista. A questão do desejo é fundamental para que não fiquemos à mercê dos consumismos, racismos, machismos e outros preconceitos que nos fazem adaptados às condições impostas pela sociedade em que vivemos.

Esta opção deve estar contida no planejamento como mais um elemento de transformação, já que, a formação de um sujeito que questione a "normalidade" da subjetividade capitalista é uma condição importante para a transformação da sociedade.

\section{A Educação Física}

Cabe agora definir o nosso caminho por dentro da Educação Física na busca da construção de uma nova sociedade e de um novo tipo de homem. Sabemos que este deve ser forjado no cotidiano das relações interpessoais, sendo assim, não podemos perder de vista que o trabalho na escola deve passar, entre outras possibilidades, pelo interior de cada disciplina.

Nesse sentido, entendemos que o paradigma da Aptidão Física, bastante presente nas nossas escolas, está diretamente ligado a uma visão de mundo que corrobora com a desigualdade, com o individualismo e com a exacerbação da competição, características da sociedade e do homem capitalista que queremos transformar.

Nesta concepção, a educação física é vista como uma prática neutra capaz de desenvolver aptidões e habilidades de acordo com a capacidade 
individual. Seus princípios se refletem na disciplina através de uma incessante busca por melhorias de desempenho baseadas nos avanços científicos nas áreas de fisiologia, biomecânica, treinamento desportivo, entre outras. O desporto de alto nível é muito valorizado tanto na sua lógica de exacerbar o espírito competitivo como para gerar melhores desempenhos. Na verdade, essa exacerbação do espírito competitivo está bem de acordo com a sociedade capitalista, já que por intermédio dela surgem indivíduos mais ou menos capazes para ocupar postos na sociedade, servindo assim como justificativa das desigualdades existentes.

Além disso, a concepção da Aptidão Física, de acordo com Coletivo de Autores (1992) preconiza a formação de um homem adaptado, disciplinado, respeitador das normas e da hierarquia bem de acordo com os estereótipos ideais para o desenvolvimento da sociedade capitalista. Com o "corpo fortalecido" o indivíduo poderá desempenhar aquilo que se espera dele nesta sociedade: competir com seus iguais por uma melhor posição na escala social, e assim aumentar a produtividade do sistema.

Os esportes são muito utilizados porque além de permitirem o exercício do alto rendimento já tem os seus modelos amplamente divulgados pela mídia. Além disso, a prática desses esportes se dá por meio de uma mecanização dos gestos que cria modelos, institucionaliza uma disciplina, tolhendo um livre conhecimento do próprio corpo.

Para se contrapor a esta visão, procuramos uma concepção de educação física que possa servir como referência em nosso cotidiano, e seja um instrumento de transformação da sociedade capitalista. Optamos, então, por utilizar como base a concepção Crítico-superadora, uma vez que esta entende que a sociedade em que vivemos não é neutra, mas que favorece uma classe social, a burguesia, em detrimento da maioria, os trabalhadores. Essa concepção tem como propósito encaminhar ações educativas que possibilitem, em última instância, a formação de sujeitos comprometidos com a superação desta sociedade.

$\mathrm{Na}$ busca de alteração dessa realidade, a concepção Críticosuperadora aponta a necessidade de uma luta pela hegemonia das idéias, neste caso, das idéias da classe trabalhadora, buscando redimensionar os conceitos morais, políticos e intelectuais de acordo com os interesses desta classe, ou seja, a busca de uma sociedade igualitária ${ }^{3}$.

Em relação à concepção de homem, a tendência crítico-superadora defende que na busca de uma nova sociedade novos valores devem ser 
afirmados. Assim, a solidariedade deve substituir o individualismo, a cooperação deve vencer a competição, a distribuição deve prevalecer sobre a apropriação, a liberdade de expressão deve levar à emancipação superando assim a dominação e a submissão do homem pelo homem.

Em relação à educação física, a concepção Crítico-superadora, presente no trabalho conhecido como Coletivo de autores (1992), defende a idéia, abraçada por nós em nosso planejamento, de que a educação física é uma disciplina que aborda os conhecimentos produzidos pelo homem acerca da cultura corporal e pretende

desenvolver uma reflexão pedagógica sobre o acervo de formas de representação do mundo que o homem tem produzido no decorrer da história, exteriorizadas pela expressão corporal: jogos, danças, lutas, exercícios ginásticos, esporte, malabarismos, contorcionismo, mímica e outros, que podem ser identificados como formas de representação simbólica de realidades vividas pelo homem, historicamente criadas e culturalmente desenvolvidas (COLETIVO DEAUTORES, 1992, p. 38).

Ou seja, entendemos que existe uma série de atividades que utilizam a expressão corporal como linguagem, que foram historicamente produzidas pelo homem e que devem ser socializadas pela escola. Essa concepção deve servir de instrumento para uma forma diferente de se apropriar desse conhecimento e também para uma outra forma de se relacionar com esses conteúdos que permitam realizar uma ruptura com as subjetividades instituídas pelo capitalismo.

\section{O PLANEJAMENTO DA EDUCAÇÃO FÍSICA}

Aqui construiremos um planejamento baseado nas concepções apresentadas anteriormente, iniciando-se pelo contexto em que iremos implementar este planejamento e atuar na busca da transformação.

\section{A Escola em Foco}

A escola em que atuamos é uma escola pública, administrada pelo Governo do Estado do Rio de Janeiro e atende majoritariamente aos moradores de uma favela que fica em frente à escola e, também, moradores de 
baixa renda de outras localidades vizinhas. Assim, os alunos dessa escola em sua maioria são de classe baixa e classe média-baixa.

A escola atende ao $3^{\circ}$ e $4^{\circ}$ ciclos ( $5^{\mathrm{a}}$ a $8^{\mathrm{a}}$ séries) do ensino fundamental e ao ensino médio. A maioria dos alunos está na faixa entre $15 \mathrm{e}$ 20 anos, muitos já trabalham ou buscam inserção no mercado de trabalho. Grande parte desses alunos vê na escola apenas uma possibilidade de obter um diploma que lhe permita conseguir um trabalho melhor.

A escola não possui um trabalho pedagógico coletivo sistemático. Isso se dá, entre outros motivos, principalmente pelas condições de trabalho a que estão submetidos seus profissionais. A escassez de material também é um problema que atinge a escola, assim como a falta de funcionários administrativos como inspetores, porteiros, vigias e serventes.

A educação física sofre com todos os males que atingem a escola começando pela falta de material. Os professores têm disponível uma quadra e uma sala para atividades corporais também utilizada para outros fins. Segundo nossas observações, a visão que os alunos, de um modo geral, têm da disciplina é a de um espaço para o exercício corporal, voltado para a prática dos esportes, para a melhoria da condição física, e até mesmo um simples espaço para divertimento.

Diante disto, entendemos que devemos buscar ampliar a visão que os alunos possuem da educação física e, interferir na visão que têm da realidade. Afinal, para construir uma nova sociedade é necessário que o aluno analise criticamente o mundo que o cerca. Para efeito, iremos apresentar nosso planejamento para a $1^{a}$ série do ensino médio. Escolhemos esta série porque é a que agrupa o maior número de turmas na escola, além de ser a série inicial do ensino médio, uma nova etapa no processo de formação, na qual o aluno começa, mais claramente, a lidar com temas ligados ao mundo do trabalho.

\section{Objetivos}

\section{OBJETIVOS GERAIS}

Os objetivos gerais estão diretamente ligados às concepções de sociedade e de homem que apresentamos anteriormente. Assim, o nosso objetivo é contribuir para a formação de um indivíduo autônomo, capaz de atuar criticamente e transformar o contexto em que vive. Nesse sentido, 
entendemos que é necessário o aluno se perceber enquanto sujeito pertencente a uma determinada classe social, pois essa noção é fundamental para que as transformações que o mesmo ajude a imprimir na sociedade venham ao encontro das necessidades do grupo ao qual pertence.

\section{OBJETIVOS ESPECÍFICOS}

Como objetivos específicos para a $1^{\text {a }}$ série, intencionamos levar o aluno a uma reflexão acerca do significado da educação física. A partir daí buscamos que o mesmo comece a ter condições de analisar criticamente a relação entre a disciplina e a realidade social. Pretendemos que o aluno tenha condições de analisar e posicionar-se frente à relação entre a nossa disciplina e a educação; questionar o peso exacerbado que a competição tem na educação física e na sociedade; analisar o papel que o esporte (mais especificamente o futebol na sociedade brasileira) desempenha no mundo atual; compreender criticamente o processo de institucionalização dos jogos e a importância deste tipo de atividade para a conformação da identidade cultural do nosso país e incentivar a valorização de outras formas de comunicação, mais especificamente a expressão corporal.

\section{Conteúdos e Estratégias}

No primeiro bimestre pretendemos iniciar discutindo a relação entre a educação e a educação física. Buscamos questionar a concepção que os alunos têm da disciplina e mostrar que a mesma desempenha um papel importante na formação, pois possui conhecimentos importantes para a compreensão da realidade. Apresentaremos diferentes concepções de educação e educação física, mostrando como essas diferenças se apresentam nas aulas e tentaremos provocar o questionamento acerca dos pressupostos em que essas aulas se baseiam, utilizando como conteúdo os esportes. Assim, nos valeremos das diferentes formas de trabalhar com suas manifestações, por exemplo, o basquete, a fim de debater o entendimento dos alunos em relação à disciplina.

Ainda nesse bimestre discutiremos o peso exacerbado que a competição tem na disciplina. Faremos isso utilizando o conteúdo jogo, procurando demonstrar a oposição entre os jogos competitivos e cooperativos, 
fazendo os alunos vivenciarem os dois tipos e debaterem sobre os pressupostos presentes em cada tipo de aula, em cada tipo de jogo.

Para o segundo bimestre, pretendemos trabalhar mais uma vez o esporte e mais especificamente o futebol. Isso porque entendemos que, além de projetar elementos da nossa cultura e valores da nossa sociedade, este é um conhecimento sempre presente no interesse de nossos alunos. Assim jogando, vivenciando as questões que surgem no jogo, poderemos discutir sobre os elementos presentes no mesmo. Por meio da prática poderemos analisar as relações estabelecidas entre os participantes e discuti-las. Desta forma, questões como o machismo, a tendência a se excluir aqueles que não sabem jogar, a competitividade exacerbada e a lógica presente na competição que reflete àquela presente na sociedade capitalista poderão ser refletidas e debatidas com os alunos.

Faremos um tribunal onde poderemos discutir questões que surgem sobre o futebol, mas que estão relacionadas com a sociedade. Com isso pretendemos ampliar a visão que os alunos têm do futebol e da sua relação com a sociedade e estimular uma análise crítica não só do futebol, como também do esporte em geral e da sociedade como um todo.

Acreditamos que a partir de um olhar mais aprofundado acerca dos fenômenos que cercam o futebol no Brasil poderemos observar, analisar e compreender o esporte como um fenômeno social e histórico importante na nossa sociedade. Assim, a partir deste entendimento, queremos deixar claro que a transformação do esporte por meio da atuação de cada um de nós, professores e alunos, faz parte da transformação da sociedade.

No terceiro bimestre pretendemos trabalhar os jogos não desportivos. Nosso intuito é que os alunos possam analisar comparativamente os elementos presentes nesse tipo de jogo e naqueles chamados desportivos. Através da prática iremos alterar as regras dos esportes e dos jogos populares de acordo com os nossos interesses, demonstrando que essas atividades devem se adaptar às nossas necessidades, e não o contrário. Esta estratégia nos permite provocar a reflexão sobre o processo de institucionalização dos jogos e de construção das regras e estimular o entendimento de que esta institucionalização é fruto da ação dos indivíduos. Estendendo esta percepção para o contexto social podemos questionar a construção das regras, das leis na nossa sociedade e refletir se essas regulamentações são favoráveis ou não à maioria da população. Ao mesmo tempo, poderemos questionar as necessidades criadas pelo mercado, que 
acabam determinando as regras (como no caso das regras do vôlei, alteradas pelas necessidades da televisão) e definindo quais as atividades que ganham status e assim podem participar de eventos como as Olimpíadas. Contra esta determinação do mercado, devemos estimular o debate acerca das nossas reais necessidades, e da possibilidade de transformar os jogos, os esportes e a sociedade de acordo com os nossos interesses.

Buscamos ainda nesse bimestre estimular um maior conhecimento da nossa cultura trabalhando com os jogos populares e discutindo seus significados. Pediremos aos alunos que tragam para a aula jogos e brincadeiras realizados por eles e por seus parentes para que os pratiquemos, fazendo assim um apanhado de jogos de regiões do país, seus nomes, formas de jogar, regras, etc. Assim, poderemos perceber o quanto essas atividades vêm passando de geração em geração, e socializar um conhecimento que apesar de pouco valorizado é importante para a constituição da nossa identidade. Aqui estaremos incentivando a percepção do aluno como um produtor/reprodutor da cultura e valorizando aquilo que parte dele em oposição às necessidades criadas pelo mercado.

No quarto bimestre nossa intenção é realizar atividades que proporcionem um contato maior com a expressão corporal. Nesse sentido, o conteúdo priorizado será a dança e teremos como tarefa para a série a construção de uma coreografia. Aqui queremos valorizar uma outra forma de comunicação, além de mostrar uma das experiências corporais produzidas historicamente pelo homem. Com a construção de uma coreografia vamos estimular o aluno a vivenciar a possibilidade de transmitir uma mensagem através de uma linguagem que não é a falada nem a escrita. Assim os alunos poderão escolher uma música e construir uma seqüência de movimentos que transmitam uma mensagem a partir da interpretação que fazem da música selecionada.

Buscamos estimular a criatividade do aluno e proporcionar a ele a vivência de um processo de construção coletiva. Neste processo, objetivamos exercitar o respeito à diferença de opiniões e a busca do consenso, sem o qual será impossível construir a coreografia. Uma reflexão acerca das relações estabelecidas durante o processo é um elemento importante para discussão e para a compreensão de que as questões que aparecem nos grupos são um reflexo dos valores dos participantes e da sociedade e devem ser transformadas quando não contribuem para que possamos viver melhor. 


\section{A avaliação}

Ao nosso ver os princípios que regem a avaliação devem estar em consonância com a sociedade e o homem que se quer formar. Assim consideramos o aluno como participante, e não como um objeto, realizando uma avaliação compartilhada. Nesse sentido, entendemos que as informações devem estar acessíveis não só para o professor, mas também para o aluno, que assim possui instrumentos para ser sujeito do seu próprio processo de transformação. A avaliação deve ser considerada um processo que se dá a todo momento e que sempre nos fornece informações para alterações no nosso percurso. Não podemos deixar que ela seja pontual, reduzida aos momentos de "prova". Ela deve ser diagnóstica, e não classificatória, porque não pretendemos classificar, nem tampouco criar hierarquias entre os alunos, mas observar a todo instante se eles estão caminhando na direção dos objetivos propostos. Isso possibilita que possamos mudar as estratégias se entendermos que não estamos avançando na direção desejada. A avaliação não deve ser punitiva, mas um estímulo à busca da melhoria de uma forma permanente.

Diante do que foi exposto para cumprir com a obrigação burocrática de dar ao aluno uma nota ou conceito, pretendemos valorizar a participação do aluno nas aulas e nas tarefas e, junto com ele, discutir como está essa participação. Nesse caminho, pretendemos estimular e valorizar a reflexão crítica do aluno sobre a sua participação, sobre a disciplina e as relações que esta estabelece com a escola e com a sociedade. Sendo assim, em todos os momentos, inclusive naqueles que fazem parte do cumprimento da obrigação da nota, estaremos propondo que o aluno exercite a sua reflexão crítica e que juntos possamos avaliar os seus avanços na compreensão da realidade. Faremos isso sem perder de vista que o momento de cada um deve ser respeitado, assim como as características individuais, valorizando mais o empenho e disposição em avançar.

\section{CONSIDERAÇÕES FINAIS}

Construindo o planejamento desta forma, entendemos que estamos atendendo os pressupostos que defendemos desde o início deste texto. Mostramos a importância de basear o nosso trabalho nos nossos referenciais de sociedade e homem. Por isso eles estão presentes nos 
objetivos, nos temas que escolhemos, na forma em que pretendemos abrangê-los, nas atividades propostas e na avaliação.

Planning for physical education in schools:

A possible path for the education of a new human being

\begin{abstract}
This text aims at pointing at the importance of plan-making based on a reference of society and of humankind. From this starting point it presents a model of planning for physical education in schools based on a concept of society and of human beings.

KEY-WORD: planning - physical education in schools

El planeamiento de la educación física de la escuela: Una manera posible para la formación de un nuevo hombre

\section{RESUMEN}

Este texto procura señalar la importancia de construirse una planificación basada en una referencia de sociedad y de hombre. A partir de ello presenta un ejemplo de planificación para la educación física escolar basado en una concepción de sociedad y de hombre.

PALABRAS-CLAVE: planificación - educación física escolar.
\end{abstract}

\title{
NOTAS
}

1 A diferença entre indivíduo e subjetividade afirmada por Guattari e Rolnik (1986) estabelece que no primeiro caso existe uma produção em série, uma modelização, uma centralização no corpo que totaliza determinadas características "dentro de si”. Já a subjetividade é uma multiplicidade, não é passível de ser totalizada, centralizada, pois é essencialmente social, circulante em todos os processos de produção sejam eles sociais ou econômicos. Para o autor, a maneira como os indivíduos se relacionam com a subjetividade pode variar entre dois extremos: "uma relação de alienação e opressão, na qual o indivíduo se submete à subjetividade tal como a recebe, ou uma relação de expressão e criação, na qual o indivíduo se reapropria dos componentes da subjetividade", produzindo a singularização (1986, p. 33).

2 Para o autor, as lutas do desejo são aquelas ao "nível do indivíduo, do casal, da família, da escola, do grupo militante, da loucura, das prisões, da homossexualidade, etc." (GUATTARI, 1987, p. 20). 
3 Para Gramsci, uma classe mantém o seu domínio sobre outra não só pelo uso da força, mas também pela capacidade de criar um consenso em torno de suas idéias que as tornam idéias de toda a sociedade. Segundo Bottomore (2001, p. 177), Gramsci afirma que a classe dominante é capaz de "ir além de seus interesses corporativos estreitos, exercendo uma liderança moral e intelectual e fazendo concessões, dentro de certos limites, a uma variedade de aliados unificados num bloco social de forças [...] esse bloco representa uma base de consentimento para uma certa ordem social, na qual a hegemonia de uma classe dominante é criada e recriada numa teia de instituições, relações sociais e idéias".

\section{REFERÊNCIAS}

BOTTOMORE, Tom. Dicionário do Pensamento Marxista. Rio de Janeiro: Jorge Zahar, 2001.

COLETIVO DE AUTORES. Metodologia do ensino de educação física. São Paulo: Cortez, 1992.

COUTINHO, Carlos Nelson. Democracia e socialismo no Brasil hoje. In: IBASE (Org.). A democracia como proposta. Rio de Janeiro: Ibase, 1991.

A democracia como valor universal e outros ensaios. Rio de Janeiro: Salamandra, 1984.

FRIGOTTO, Gaudêncio. Educação e crise do capitalismo real. São Paulo: Cortez, 1995.

GUATTARI, Felix. Revolução Molecular: pulsações políticas do desejo. 3. ed. São Paulo: Brasiliense, 1987.

GUATTARI, Felix \& ROLNIK, Sueli. Micropolítica cartografias do desejo. Petrópolis: Vozes, 1986.

HOBSBAWM, Eric. Adeus a tudo aquilo e Renascendo das cinzas. In: BLACKBURN, Robin. Depois da queda. Fracasso do comunismo e o futuro do socialismo. Rio de Janeiro: Paz e Terra, 1992.

LIBÂNEO, José Carlos. Didática. São Paulo, Cortez, 1994. 
LUCKESI, Cipriano C. Avaliação da aprendizagem escolar. 8. ed. São Paulo: Cortez, 1998.

OLIVEIRA, Francisco de. O surgimento do antivalor: capital, força de trabalho e fundo público. Revista Novos Estudos - CEBRAP. São Paulo, n. 22, p. 8-28, out. 1998, e Collor - A falsificação da ira. Rio de Janeiro: Imago, 1992.

WEFFORT, Francisco C. Por que democracia? São Paulo: Brasiliense, 1984.

Recebido:30 de abril de 2004

Aprovado: junho de 2004

Endereço para correspondência

Travessa Pepe 10/503

Botafogo - Rio de Janeiro - RJ

CEP 22290-020

E-mail:msayao@montreal.com.br 
